\title{
Free radical generation by neutrophils: a potential mechanism of cellular injury in acute alcoholic hepatitis
}

\author{
A J K WILLIAMS AND R E BARRY \\ From the University Department of Medicine, Bristol Royal Infirmary, Bristol
}

SUMMARY Liver membrane vesicles were prepared from operative liver biopsies from six patient volunteers undergoing abdominal surgery for non-hepatic disease. Neutrophils were extracted from their blood. The liver membrane vesicles were exposed to $1 \mathrm{mmol} / \mathrm{l}$ acetaldehyde with or without reduction of the resultant adducts formed. The production of superoxide anion by the neutrophils upon exposure to the liver membrane vesicles prepared from the same patient was assessed by measuring the rate of cytochrome $c$ reduction before and after the addition of superoxide dismutase. Preincubation with acetaldehyde significantly increased superoxide production in response to both the reduced (from $35 \cdot 5 \pm 7 \cdot 1 \mathrm{nmol} \mathrm{O}-/ 10^{\star}$ cells $/ \mathrm{min}$ to $128 \pm 25$, mean \pm SEM, $p<0 \cdot 01$ ) and the non-reduced liver cell membranes (from $17 \cdot 2 \pm 4 \cdot 3$ to $81 \pm 17$, $\mathrm{p}<(0 \cdot 01) ; 1 \mathrm{mmol} / \mathrm{l}$ acetaldehyde alone caused no superoxide production. Neutrophil free radical production in response to acetaldehyde altered hepatocyte membranes could be an important mechanism of cellular injury in acute alcoholic hepatitis.

Acetaldehyde is the primary metabolite of ethanol. It has been shown to bind non-enzymatically (via the formation of an intermediary Schiff base) to hepatocyte membranes.' This could result in morphological changes, and the generation of new antigenic determinants in the liver cell membrane, both of which have recently been described in response to ethanol, ${ }^{23}$ with evidence in the later that acetaldehyde is responsible.

Neutrophilic infiltration of the liver is a characteristic feature of acute alcoholic hepatitis. ${ }^{+}$Neutrophils can produce free superoxide anions through the function of an oxidase enzyme in the cell surface membrane.' Superoxide anion damages cells, and has been postulated as causing alcoholic liver injury."

It has previously been shown that acetaldehyde altered hepatocyte membranes will activate complement, ' and we have recently shown that acetaldehyde-altered liver cell membranes will

Address for correspondence: Dr A Williams, University Department of Medicine. Bristol Royal Infirmary, Bristol BS2 8HW

Received for publication 19 February 1987. stimulate neutrophil superoxide production and degranulation in the rat. ${ }^{* 4}$

The purpose of this study was to investigate the effect of acetaldehyde-altered hepatocyte membranes upon neutrophil superoxide production in man, and the potential relevance of this to hepatocyte injury in acute alcoholic hepatitis.

\section{Methods}

PATIENT VOLUNTEERS

Wedge hepatic biopsies were obtained from six patient volunteers who gave informed consent, and whose livers were being exposed during the course of elective surgical treatment of non-hepatic disease. Hospital ethical committee approval was given for the study. All patients had normal biochemical liver function tests, no history of alcohol abuse, and a macroscopically normal liver at operation.

LIVER MEMBRANE PREPARATION

The liver biopsies were immediately homogenised at $0-4^{\circ} \mathrm{C}$, and plasma membrane vesicles were prepared by a rapid Percoll stepped centrifugation technique." 
After preparation the plasma membrane vesicles were frozen in liquid nitrogen and stored at $-20^{\circ} \mathrm{C}$ until used. The membrane purity was assessed by measuring the enzymes 5'-nucleotidase (EC 3.1.3.5) and glucose-6-phosphate (EC 3.1.3.9) markers for plasma membranes and endoplasmic reticulum respectively." I' Microscopy using a Phillips 300) transmission electron microscope confirmed the presence of vesicles.

\section{NEUTROPHIL PREPARATION}

Neutrophils were prepared in a standard fashion " by dextran sedimentation and subsequent FicollHypaque centrifugation of blood taken from the volunteers who had undergone operative liver biopsy. This enabled neutrophils, and liver cell membrane vesicles from the same donor to be used in each experiment. The neutrophils were washed with phosphate buffered saline (PBS) $\mathrm{pH} 7 \cdot 4$ three times, and then resuspended in PBS $\mathrm{pH} 7 \cdot 4$. Over $95 \%$ of the neutrophils prepared by this technique were viable as assessed by the exclusion of Trypan blue.

\section{INCUBATION EXPERIMENTS}

As previously described the human liver plasma membrane vesicles containing $1 \mathrm{mg}$ protein were incubated in $100 \mathrm{mmol} / \mathrm{l} \mathrm{Hepes} \mathrm{buffer,} \mathrm{pH} 7.5$ with or without $1 \mathrm{mmol} / \mathrm{l}$ acetaldehyde at $18^{\circ} \mathrm{C}$ for two hours. The acetaldehyde adducts formed were either left non-reduced or stabilised by reduction by including in the incubation $20 \mathrm{mmol} / \mathrm{l}$ sodium cyanoborohydride, and $2 \mathrm{mmol} / \mathrm{l}$ nickel chloride. ${ }^{14}$ At the end of the incubation the membrane vesicles were spun down, and resuspended in $\mathrm{PBS} \mathrm{pH} 7.4$ ready for exposure to neutrophils.

\section{SUPEROXIDE ANION PRODUCTION}

This was assessed by measuring the rate of reduction of cytochrome $\mathrm{c}$ in a dual wavelength spectrophotometer before and after the addition of superoxide dismutase $e^{1 *}$ in response to exposure of the neutrophils $\left(2 \times 10^{\prime \prime}\right.$ cells $\left./ \mathrm{ml}\right)$ to the stimulus under evaluation (5) $\mu \mathrm{l}$ of a suspension containing $2 \mathrm{mg}$ membrane $p r o t e i n / \mathrm{ml}$ in PBS $\mathrm{pH} 7 \cdot 4$ in a final volume

Table Efficiency of the livermembrane preparation as assessed by marker enzymes ( $\mu \mathrm{mol} / \mathrm{h} / \mathrm{mg}$ protein)

\begin{tabular}{|c|c|c|c|}
\hline Enzyme & $\begin{array}{l}\text { Wholeliver } \\
\text { homogenate }\end{array}$ & $\begin{array}{l}\text { Liverplasma } \\
\text { membrane } \\
\text { lesicles }\end{array}$ & $\begin{array}{l}\text { Enrichment } \\
\text { factor }\end{array}$ \\
\hline $\begin{array}{l}\text { 5'-nucleotidase (plasma } \\
\text { membrane marker) }\end{array}$ & $2 \cdot 3 \pm 1 \cdot 1$ & $25 \cdot 6 \pm 6.5$ & 11 \\
\hline $\begin{array}{l}\text { Glucose-6-phosphatase } \\
\text { (cndoplasmic } \\
\text { reticulum marker) }\end{array}$ & $4 \cdot 2 \pm(0 \cdot 83$ & $10 \pm 3 \cdot 8$ & $2 \cdot 4$ \\
\hline
\end{tabular}

of $1 \mathrm{ml}$ ). A standard stimulus, 4 (3-phorbol, 12 myristate, 13 acetate (PMA) in a final concentration of $5 \mu \mathrm{g} / \mathrm{ml}$ was also used.

\section{STATISTICAL ANAIYYSIS}

Results are expressed as mean values \pm standard error of mean (SEM) and statistical analysis was carried out with the Students $t$ test for paired results.

\section{Results}

The purity of the liver plasma membrane vesicles as shown in the Table is comparable with results described by others using the same or a similar technique. " 11 There is an 11-fold increase in the 5 'nucleotidase activity in the membrane fraction compared with the liver homogenate, but with some contamination with smooth endoplasmic reticulum as noted by a $2 \cdot 4$-fold increase in glucose-6phosphatase activity.

The Figure shows that pre-exposure of the hepatocyte membrane vesicles to acetaldehyde significantly increased superoxide anion production by the neutrophils both in response to the reduced samples from $35 \cdot 5 \pm 7 \cdot 1 \mathrm{nmol} \mathrm{O}-10^{*}$ cells $/ \mathrm{min}$ to $128 \pm 25 \mathrm{nmol}$ $\mathrm{O}_{2}^{-} / 10^{\times}$cells/min, $\mathrm{p}<0 \cdot(01 ;$ and the non-reduced samples from $17 \cdot 1 \pm 4 \cdot 3 \mathrm{nmol} \mathrm{O}_{2}^{-} / 10^{*}$ cells $/ \mathrm{min}$ to $81 \cdot 3 \pm 17 \mathrm{nmol} \mathrm{O}-/ 10^{*}$ cells $/ \mathrm{min}, \mathrm{p}<0 \cdot 01$.

There was no statistical difference between the

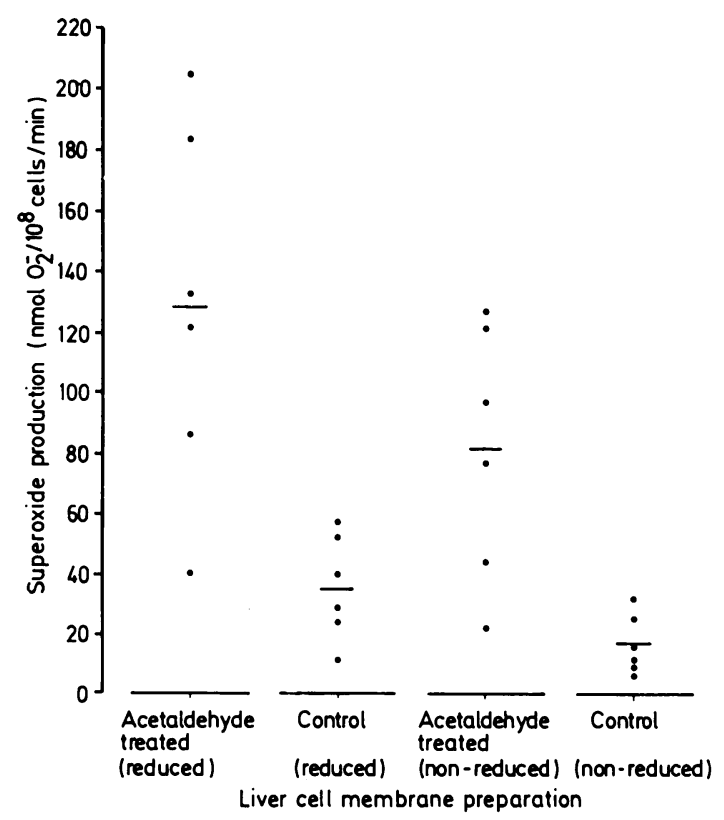

Figure Neutrophil superoxide production in response to acetaldehyde altered and control liver plasma membrane vesicles (reduced and non-reduced). 
reduced and non-reduced acetaldehyde treated membranes in their ability to stimulate neutrophil superoxide production. The reduced control membranes (not exposed to acetaldehyde but exposed to sodium cyanoborohydride) did significantly increase superoxide production when compared with control membranes which had not been reduced $(p<0 \cdot 01)$.

Exposure of the neutrophils to $1 \mathrm{mmol} / \mathrm{l}$ acetaldehyde alone caused no free radical production.

The response of the neutrophils to PMA which is recognised as a stimulus causing near maximal production of superoxide anion was $232 \pm 28 \mathrm{nmol} \mathrm{O}_{2}^{-} / 10^{8}$ cells/min, similar to that reported by other workers. ${ }^{16}$

\section{Discussion}

These experiments show that acetaldehyde altered liver plasma membranes will cause neutrophils to produce superoxide anion. Oxygen derived free radicals are important mediators of inflammation and tissue injury, and are known to be cytotoxic and may therefore cause hepatocyte injury and death. ${ }^{17}$ Superoxide is itself cytotoxic, but its generation can also lead to the formation of other highly reactive species, ${ }^{18}$ such as the hydroxyl radical which is also potentially hepatotoxic.

Previous attention has focused on intracellular sources of superoxide anion in alcoholic liver disease with xanthine oxidase the principal enzyme implicated. ${ }^{6}$
Acetaldehyde

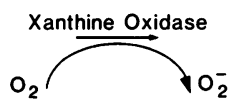

tions of acetaldehyde $(20-100 \mu \mathrm{mol} / \mathrm{l})$ reported in the systemic circulation of alcoholics ${ }^{22}$ but the concentrations of acetaldehyde achieved in the liver during alcohol abuse are not known and may be considerably in excess of this because over $95 \%$ does not enter the blood stream. ${ }^{23}$

Acetaldehyde alone caused no increase in neutrophil superoxide production. Therefore any effect because of pre-exposure must be as a result of membrane alterations caused by acetaldehyde. Acetaldehyde could react with the liver membrane proteins in two ways. First, it could be released extracellularly and then combine with the plasma membrane proteins in the outer aspect of the hepatocyte cell wall. Second, because the microsomal ethanol oxidising system assumes increasing importance in the metabolism of ethanol to acetaldehyde in those who abuse alcohol, ${ }^{24}$ acetaldehyde produced locally in the smooth endoplasmic reticulum could bind to membrane proteins being assembled for translocation to the cell surface for incorporation in the inner and outer aspects of the hepatocyte cell wall. This would be in keeping with current concepts of plasma membrane biogenesis. ${ }^{25}$

The covalent binding of acetaldehyde to the free amino groups of lysine residues in liver membrane proteins could result in alteration of the tertiary or quaternary structure of the proteins, thus making the liver membrane proteins more immunogenic.

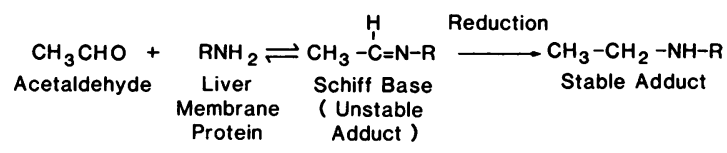

The metabolism of acetaldehyde to acetate promotes the reduction of molecular oxygen to the superoxide anion.

We have shown that superoxide can be released extracellulary by the stimulation of the neutrophil oxidase enzyme in response to acetaldehyde altered liver cell membranes. The extracellular release of oxygen derived free radicals by macrophages has previously been shown to promote hepatic injury which can be prevented by using scavengers of superoxide anion. ${ }^{19}$ Increased hepatic lipid peroxidation $^{20}$ and decreased hepatic glutathione concentrations $^{21}$ in man, rat, and baboon in response to alcohol have been described. This implies increased superoxide production because singlet oxygen and hydroxyl radicals are scavenged by glutathione and oxygen derived free radicals cause the peroxidation of unsaturated lipids in cellular membranes.

A concentration of $1 \mathrm{mmol} / \mathrm{l}$ acetaldehyde was chosen as previous work has shown that the binding sites on hepatocyte plasma membranes are saturated at this concentration. ${ }^{7}$ This is higher than concentra-
The number of acetaldehyde adducts which become stable (reduced) spontaneously has been variously reported as between $25-80 \%$ of the total number of adducts (stable and unstable). ${ }^{21}{ }^{22}$ In an attempt to increase the number of stable adducts in our experiments reduction was performed with sodium cyanoborohydride to convert any unstable adducts present to stable ones. We were unable to show a difference, however, between the acetaldehyde treated and reduced membranes (which would have stable adducts only), and the acetaldehyde treated but non-reduced membranes (which would have stable and unstable adducts). If a maximal response had been achieved with the acetaldehyde treated but non-reduced samples, a further increase in the number of stable adducts would have no additional effect upon superoxide production.

Eighty per cent of the plasma membrane vesicles prepared by this technique are correctly orientated that is, sealed outside-out."

We feel an immunological hypothesis for the 
pathogenesis of acute alcoholic hepatitis and subsequent cirrhosis is more in keeping with the inherent individual susceptibility to the effects of alcohol abuse than is the direct hepatoxity of ethanol or its metabolites. Previous work by our group has shown that acetaldehyde altered liver plasma membranes will activate the complement cascade. ${ }^{7}$ The C5a component produced is a potent chemotactic factor for neutrophils ${ }^{28}$ and if generated locally in the liver would attract neutrophils to the organ and could also stimulate them to produce superoxide anion.

Our experiments were carried out in protein free media, and both the neutrophil and the liver membrane vesicles were washed during preparation and extraction but it is possible that there could be some contamination with complement components or immunoglobulin.

We postulate that acetaldehyde modified liver cell membranes act as a stimulus to the neutrophil to liberate superoxide anion as a consequence of a membrane interaction. Although a number of stimuli for superoxide release have specific receptors on the neutrophil (C5a, f MLP, Fc complement of IgG, $\mathrm{LTB}_{4}$, platelet activating factor) there are many stimuli which act via a membrane interaction which do not have specific receptors but for whom recognition is possible as shown by increasing superoxide production - for example, kallikrein, latex beads, crystals (urate, hydroxyapatite), lectins, endotoxins, fatty acids.

It could be that the neutrophil recognises the surface charge effect induced by the formation of the acetaldehyde adducts with the loss of the positive charge normally bourne by the free amino groups of the lysine residues at physiological $\mathrm{pH}$ (so there will be a net excess of basic groups). Urate and hydroxyapatite crystals are felt to activate neutrophils through a surface charge effect. ${ }^{29}$

Alternatively the binding of acetaldehyde to the free amino groups of lysine residues in liver membrane proteins through the loss of charge on these groups could result in profound changes in the tertiary or quarternary structure of these proteins and the conformational changes induced could unmask previously unrecognised receptors for neutrophil activation. This could be in an analogous fashion to the expression of neoantigens by the hepatocyte in response to ethanol which has recently been described where acetaldehyde appears to be responsible. ${ }^{3}$

This paper shows that once present within the liver, acetaldehyde altered hepatocyte membranes could stimulate the neutrophil to produce superoxide anion with hepatotoxic consequences. This is a potentially important mechanism of cellular injury in acute alcoholic hepatitis.
A Williams is a Wellcome Research Fellow. We would like to thank Professor Williamson, Mr Baird and $\mathrm{Mr}$ Webb, consultant surgeons at the Bristol Royal Infirmary for allowing us to approach their patients, and for the performance of operative liver biopsies. We wish to thank the Wellcome Trust for supporting this work, and Miss V Blake for secretarial help.

\section{References}

1 Barry RE, McGivan JD, Hayes M. Acetaldehyde binds to liver cell membranes without affecting membrane function. Gut 1984; 25: 412-16.

2 Yamada S, Mak KH, Lieber CS. Chronic ethanol consumption alters rat liver plasma membranes and potentiates release of alkaline phosphatase. Gastroenterology 1985; 88: 1799-806.

3 Crossley IR, Neuberger J, Davis M, Williams R, Eddleston ALWF. Ethanol metabolism in the generation of new antigenic determinants on liver cells. Gut 1986; 27: 186-9.

4 Scheuer PJ. The morphology of alcoholic liver disease. Br Med Bull 1982; 38: 63-5.

5 Goldstein IM, Cerquerira M, Lind S, Kaplan HB. Evidence that the superoxide generating system of human leukocytes is associated with the cell surface. $J$ Clin Invest 1977; 59: 249-54.

6 Lewis KO, Paton A. Could superoxide cause cirrhosis? Lancet 1982; ii: 188-9.

7 Barry RE, McGivan JD. Acetaldehyde alone may initiate hepatocellular damage in acute alcoholic liver disease. Gut 1985; 26: 1065-9.

8 Williams AJK, Barry RE. Acetaldehyde altered liver membranes stimulate neutrophils in the rat. [Abstract]. Gut 1986; 27: A615.

9 Williams AJK, Barry RE. Superoxide production and degranulation of rat neutrophils in response to acetaldehyde altered liver cell membranes. Clin Sci 1986; 71: 313-8.

10 Epping RJ, Bygrave FL. A procedure for the rapid isolation from rat liver of plasma membrane vesicles exhibiting $\mathrm{Ca}^{2+}$-transport and $\mathrm{Ca}^{2+}$-ATPase activities. Biochem J 1984; 223: 733-45.

11 Hepel LA, Himlow RJ. Methods in enzymology. Vol II. New York: Academic Press, 1955: 566.

12 Swanson MA. Methods in enzymology. Vol II. New York: Academic Press, 1955: 541-3.

13 Segal AW, Peters TJ. Analytical subcellular fractionation of human granulocytes with special reference to the localization of enzymes involved in microbicidal mechanisms. Clin Sci Mol Med 1977; 52: 429-42.

14 Jentoft N, Dearborn DG. Labelling of proteins by reductive methylation using sodium cyanborohydride. J Biol Chem 1979; 254: 4359-65.

15 Cross AR, Higson FK, Jones OTG. The enzymatic reduction and kinetics of oxidation of cytochrome b-245 of neutrophils. Biochem J 1982; 204: 479-85.

16 Yamashita T, Soneya A, Hara E. Response of superoxide anion production by guinea pig eosinophils to 
various soluble stimuli: comparison to neutrophils. Arch Biochem Biophys 1985; 241 : 447-52.

17 Halliwell B, Gutteridge JMC. Free radicals in biology and medicine. Clarendon Press: Oxford, 1985: 118.

18 Halliwell B, Gutteridge JMC. The importance of free radicals and catalytic metal ions in human disease. $\mathrm{Mol}$ Aspects Med 1985; 8: 89-193.

19 Arthur MJP, Bentley IS, Tanner AR, Saunders PK, Millward-Sadler GH, Wright R. Oxygen derived free radicals promote hepatic injury in the rat. Gastroenterology 1985; 89: 1114-22.

20 Dianzani MU. Lipid peroxidation in ethanol poisoning a critical reconsideration. Alcohol Alcoholism 1985; 20: 161-73.

21 Shaw S, Rubin KP, Lieber CS. Depressed hepatic glutathione and increased diene conjugates in alcoholic liver disease. Dig Dis Sci 1983; 28: 585-89.

22 Nuutinen H, Lindros KO, Salaspuro M. Determinants of blood acetaldehyde level during ethanol oxidation in chronic alcoholics. Alcohol Clin Exp Res 1983; 7: 163-7.

23 Erikson CJP, Sippel HW. The distribution and meta- bolism of acetaldehyde in rats during ethanol oxidation. Biochem Pharmacol 1977; 26: 241-7.

24 Lieber CS. Alcohol metabolism. In: Hall P, ed. Alcoholic liver disease: pathobiology, epidemiology and clinical aspects. London: Edward Arnold, 1985; 3-40.

25 Morre DJ, Kartenbech J, Franke WW. Membrane flow and interconversions among endomembranes. Biochem Biophys Acta 1979; 559: 71-152.

26 Donohue TM, Tuma DJ, Sorrell MF. Acetaldehyde adducts with proteins: binding of $\left[{ }^{14} \mathrm{C}\right]$ acetaldehyde to serum albumin. Arch Biochem Biophys 1983; 220: 239-46.

27 Medina VA, Donohue TM, Sorrel MF, Tuma DJ. Covalent binding of acetaldehyde to hepatic proteins during ethanol oxidation. J Lab Clin Med 1985; 105: $5-10$.

28 Roitt I. Essential immunology. 5th ed. Oxford: Blackwell Scientific Publications, 1984: 168.

29 Higson FK, Jones OTG. Oxygen radical production by horse and pig neutrophils induced by a range of crystals. J Rheumatol 1984; 11: 725-40. 